\title{
TRES NOVELITAS BURGUESAS Y LO ALEATORIO DE LOS EVENTOS
}

\author{
Lidia Neghme Echeverría
}

\section{INTRODUCCION}

En la revista Communications $n^{\circ} 18$ Edgar Morin (1) selecciona ensayos que refuerzan la idea del retorno del acontecimiento. Relaciona este problema teórico con conquistas científicas: fragmentación de los rayos por efecto Doppler. Vincula la teoría de la relatividad (tiempo unido al espacio) con el surgimiento del acontecimiento.

Utilizamos, para analizar Tres Novelitas Burguesas de José Donoso, el ensayo de Abraham Moles, contenido en el número organizado por Morin. Moles estudia la representación de los eventos, estableciendo nexos entre la esfera privada del personaje y su universo social. Nos señala la dimensión que ellos poseen: micro-eventos (llegan a la conciencia y se borran inmediatamente), mini-eventos (se retienen durante un período variable de tiempo, siempre limitado por la duración de la vida - un mes, un día), y eventos propiamente dichos; memorizados por aquellos que han participado o sido testigos (2)

\subsection{Los acontecimientos en las "tres novelitas"}

"Chatanooga Choochoo", "ÁTOMO VERDE NUMERO CINCO" y "Gaspard de la Nuit" son las "tres novelitas" de Donoso. Articulan una masa de eventos.

La mayor parte de los acontecimientos, según Moles imprevisibles, revelan "la notion d'un setting ou d'un décor de l'événement"

(1) - Véanse, especialmente, los dos ensayos de E. Morin: "Le retour de l'événement" (pp. 6-20) y, 'L'événement-sphinx" (pp. 173-192), Communications, Paris, Seuil, no 18, 1972.

(2) - Cf. el artículo de Moles: "Note pour une typologie des événements" - Communications n' 18, Ibidem, pp. 90-96. 
(3) En "las novelitas", el plan sociocultural enmarca la incertidumbre ante lo real. Esto puede, además, ser estudiado mediante el análisis de lo fantástico y de sus aspectos: lo fantasmagórico y lo fantasmático (4)

\section{1. "Chatanooga Choochoo"}

En la "primera novelíta", la canción - Chatanooga Choochoo - le confiere el nombre al relato; reactualiza una ambiencia de los años 40 , en un mundo movido por el placer fetichista de la moda, las fruiciones burguesas de máscaras consumidas por pseudointelectuales. He aquí el juego dialéctico del "placer (cultural) y del goce (incultural)", que arma y desarma identidades y sujetos (5)

Inicialmente, la canción funcionará como micro-evento (para Anselmo) Este, al percibir el carácter imprevisible del setting inaugurado por Magdalena (su esposa) y Sylvia, no sabe cómo, por qué, esta música de los años 40, del repertorio de las Andrews Sisters, ha sido rememorada por Magdalena: bailada y cantada por ella y la modelo, unánimente, "con una coordinación tan perfecta que parecía mecánica" )6)

El baile de ambas crea un ornato u escenografía. Se evidencia el grado de implicación entre la actitud de Magdalena ("sobria y más bien tímida", p. 21) y la posición de observador de su esposo. Este, al percibir lo artificioso de la evocación arbitraria, siente la modificación que se ha producido en la esfera privada de su mujer, y en la suya, mediante el micro-evento circunstancial (la canción) Ella alterará, además, el universo social de la pareja: actitud inhabitual de Magdalena, que Anselmo considera fruto de una enigmática "convulsión cerebral"> "palabras absurdas">circunstancias desconocidas por él para que sua esposa la guarde en su memoria.

La desorientación de Anselmo, ante la figuración caricatural de su esposa, se problematiza mediante "gestos de escritura", que injer-

(3) - Idem, Ibidem, p. 91 .

(4) - Vea el ensayo de Jean Bellamin-Nöel: "Notes sur le fantastique; (Textes de Théophile Gautier)" Paris, Larousse $\mathrm{n}^{\circ} 8$, dézembre de 1972, pp. 3-23. Bellamin- Nöel explica que lo fantasmagórico, técnica narrativa, provoca el desdoblamiento de la (s) narrativa (s) y, por ende, la desorientación del narrador, del héroe y del lector, que no saben cómo explicar los acontecimientos. Lo fantasmático, a su vez, consiste en poner en escena a los "fantasmas" en sentido freudeano. Art. cit., pp. 3-10.

(5) - Vea el libro de $\mathbf{R}$. Barthes - $O$ Prazer do Texto. Trad. port. de J. Guinsburg. São Paulo, Perspectiva, 1977, pp. 81-83.

(6) - "Chatanooga Choochoo" In: Donoso, José - Tres Novelitas Burguesas. Barcelona, Seix Barral, 1973, p. 21' 
tan la ambigüedad de la situación y la mostración de una textura ambivalente (7)

El referente muestra y oculta lo real. Anselmo, narrador en primera persona, definirá a Magdalena y a Sylvia como "dos muñecas" > "dos perfiles" $>$ "dos cuellos", "dos sonrisas magistralmente coordinadas" (pp. 22-23)

Las metonimias (perfiles $>$ cuellos $>$ sonrisas) patentizan la reificación, hecha por el narrador. Este no soporta la transgresión de la esfera íntima y del universo social, efectuada por su esposa. La canción, en primeira instancia, se concatena con la imagen deseada de Magdalena. Esto articula la complejidad del micro-evento, que pasa a ser, ahora, mini-evento para el marido, pues la retiene en la duración de la fiesta, ligándola al valor sorpresa y a lo imprevisible.

Se sugiere la problemática ideológica, central, de la novelita, mediante el hilo conductor, que nos refiere Chatanooga Choochoo: Please gimme a shine. I can afford to go / To Chatanooga station" ( $p$. 20)

Al inicio, la canción enclava, ambiguamente, la confluencia de Sylvia y Magdalena, delante del catálogo social de sus respectivos compañeros. Mediante la representación onomatopéyica (Gimme, gonna) y lúdica, en el presente, de una canción fruida en el pasado (años 40), se imagina toda una praxis social (fiesta) Apunta las relaciones entre su vida (esfera íntima que las obliga a obedecer $>$ ser pasivas > muñecas desmontables de sus hombres) y la atopía de sus universos sociales: la imposibilidad de asumir con placer su situación, el sin salida de un esquema de vida alienante, programado por los varones. Se trata de un feed-back, o estructura regresiva/progresiva de conservación de un aprendizaje para autocorregir el sistema y enfrentar el acontecimiento (8)

La implicación entre Chatanooga Choochoo y algunos mini-eventos del relato se verá en la urbanización. Como Magdalena no puede ir, Sylvia la califica de "mujercita sumisa" (p. 28) El interés de ésta por Magdalena altera la esfera privada (pelea, Ramón desmonta a Sylvia) y el universo social de la pareja (él se va y deja solo a Anselmo con Sylvia)

A partir de este mini-evento, comienzan a revelarse mecanismos fantasmagóricos. Esta técnica narrativa (Bellamin-Nöel) subraya la

(7) - Bellamin-Nöel afirma que la ambigüedad y el contexto espacial fantasmagórico se sustentan a través de "gestos de escritura" Cf. art. cit., pp. 3-10. 9-10.

(8) - Cf. el ensayo citado de E. Morin: "Le retour de le événement", pp.

Cf. el ensayo citado de E. Morin: "Le retour de la evénément", pp. 9-10. 
irresolución o desorientación del narrador (Anselmo), del personaje (Sylvia) y de los lectores, que no saben cómo explicar la complejidad de los eventos. Los "gestos de escritura" patentizan la máscara de Sylvia: "mujer objeto", en su esfera privada, y figuración de la "liberación", en "las páginas de revistas femeninas", (p. 30)> universo social.

En el plan narrativo, el ámbito de la canción ("I used to call Funny Face", p. 22), adquirirá sentido. Los "gestos de escritura" resaltan la gradación fantasmagórica, que torna verosímil lo narrado. Anselmo, narrador-personaje, compara a Sylvia desmontada con la "mariposa nocturna", que pudiera estarse "golpeando ciega y sin defensa" (p. 37)

Se siente "sorprendido" y "horrorizado", pero "no demasiado" (ya había escuchado que esto le sucedía a Sylvia, en la fiesta, p. 19) al ver la caricatura reificada de la modelo: "cuerpo incompleto" $>$ "sin cara"> "ojos sugeridos">la boca, las orejas ausentes > silueta es "lo único vivo y unitario" (p. 39)

Esto le confiere peso a la caricatura de Sylvia. Patentiza la ambivalencia de su máscara de modelo (universo social>exigencia de inventarse rostros $>$ necesidad de ser maquillada $>$ completada) y de mujer (posibilidad de ser desmontada $>$ anulada por su hombre $>$ esfera privada) Lo fantasmático se une aquí a lo fantasmagórico. Se evidencia por las transformaciones de Sylvia y sus potencialidades lúdicas. El narrador refiere su "figura fantasmal" (p. 38) y "la infinita posibilidad de transformaciones que producía el amor con Sylvia" (p. 54) Se connotan ambos como "envoltorios diferentes y cambiables" (p. 54), recreando una de las ideas centrales de $E l$ Obsceno Pájaro de la Noche (1970), personificada, allí, por el Mudito. Pero no existe, aquí, la ambiencia folklórica del "imbunche"

Es una tentativa de organizar, inconscientemente, el sentido: de mostrarlo y ocultarlo simultâneamente. Los "envoltorios" patentizan el fantasma de las identidades. Este revela verdades en imágenes ("envoltorios diferentes") y muestra los fantasmas que transgreden lo real. En este caso, el fantasma de las identidades, unido al deseo sexual de Anselmo por Sylvia, desemboca en el fantasma de la desaparición del órgano sexual del varón. Es ésta una instancia, paralela, a la posibilidad de borrarle los sentidos, con Vanishing Cream, a Sylvia, que el narrador posse, así como Ramón.

Se ha difundido un programa del tipo mass-media. Sylvia con su Vanishing Cream y su imagem desmontada consigue "descoyuntar la vida" de Anselmo (p. 54), borrarle el sexo. Altera la esfera privada y el universo social de éste. Tal "gesto de escritura" problematiza 
la ambigüedad de la situación, se implica con el final de la canción: "I used to call Funny Face / She's gonna cry / Until I promise nevermore" ( $p$. 22) Pero se torna más verosímil, en el desenlace del relato.

En la segunda reunión, en la casa de los Roig, son, ahora, los varones, Ramón y Anselmo, los que montarán la coreografía de la canción. Sus mujeres asumirán la posición de observadoras; ellos serán las víctimas. Aumenta la implicación del evento-conductor - Chatanooga Choochoo - por la inversión de papeles y de la situación inicial.

La concatenación de los eventos resalta la recuperación de la canción, mediante una praxis subvertida; instaura relaciones de imitación del objeto-fetiche Chatanooga Choochoo en el espacio artificial de la casa de los Roig. La duplicación de esta praxis marca lo ideológico en los niveles de la representación. La canción hace que el narrador (Anselmo) considere a Ramón como su "doble" Ambos están vestidos iguales, así como ocurriera con Sylvia y Magdalena en la primera fiesta. Esta entropía, proporcionada por una redundancia paralelística, transgrede la representación. En la rotación cíclica del cantar y bailar Chatanooga Choochoo se insertan novedades, que muestran el carácter aleatorio, de este cruce del bagaje humano.

El narrador (Anselmo) constata la ambivalencia de su identidad y la del otro. Sus relaciones con Ramón, duplicadas, revelam la castración pasiva de Anselmo, al percibir que el fantasma que complementa su identidad (Ramón) ha desaparecido "tragado por el tumulto" y que lo ha dejado "como sin mi propia imagen en el espejo para poder comprobar mi muy dudosa existencia" (p. 101).

Captamos las transformaciones del sentido, el grado fantasmático de lo real, mediante la complejidad máxima de la canción. La perplejidad de Anselmo, delante de la disolución real/irreal de su sexo y de su identidad, fantasmagoriza lo real. Advertimos un "contexto especial", el fantasma - escenario (fiesta, canción) revela la incertidumbre intelectual, fantástica, percibida por el narrador (9), mediante la inversión de papeles y el intercambio de una práctica social, organizada por sus mujeres. Ramón y Anselmo de observadores pasan a ser víctimas del sistema de vida burgués: mandar/obedecer; ser determinados/indeterminados.

La duración del relato, la redundancia de la canción, la imprevisibilidad fantasmagórica de lo real y el problema sexual del narrador (Anselmo), que patentiza el evento-catástrofe, crucial, del re-

(9) - Cf. el artículo de Bellamin-Nöel sobre lo fantástico, pp. 6-10. 
lato (pérdida del sexo y ulterior superposición de él), engloban la entropía (complejidad) de los eventos. Iluminan la fragmentación o desdoblamiento del narrador: antes del evento-catástrofe y después de él. Esto desorienta al narrador y al lector virtual. Organiza una ambigüedad fantasmagórica. Proporciona la novedad del género: sutilmente se cuestiona qué es lo real, cómo explicar lo verosímil y la contigencia del ser: esencia y apariencia al mismo tiempo.

Esto ha sido provocado por Sylvia: de víctima (Ramón la desmontó) ha pasado a ser observadora, junto con Magdalena. La modelo (mujer-objeto) transforma a Anselmo en lo que ella es para Ramón. Magdalena amplifica la práctica social asumida por su amiga. La repartición toposocial de mujeres y hombres cataliza las novedades del relato. Por ello, al devolverle el sexo a su marido, Magdalena crea una sorpresa. Altera la esfera personal de Anselmo (dominador $>$ dominado; seguro $>$ inseguro), tornándolo sumiso (canta y baila en la segunda fiesta >mutación de su universo social) Lo reduce a la caricatura de un niño. Esto puede ser unido al ámbito de la canción: "I used to call Funny Face. / Sh's gonna cry / Until I promise nevermore" (p. 22-23) Y, también, explica el desenlace, que evidencia la inversión de la situación inicial:

— "Nunca más.

Lo dije maquinalmente, contrito, porque ahora estaba seguro que Sylvia le había contado algo de nuestra aventura esa noche en la urbanización, y quería despachar mi pecado, así rápidamente y como bromeando con la promesa de un niño muy pequeño que promete observar de ahora en adelante una conducta que complazca y enorgullezca a su mamá" (p. 103)

Este mini-evento sintetiza la "autocorreción" de Anselmo, provocada por el aprendizaje a que ha sido sometido por ambas mujeres. El sistema le ha agregado una nueva organización, que destruye la anterior. Se trata de un intercambio de papeles: los varones han dejado de ser agentes observadores para asumir los que ellos les han impuesto a sus mujeres: ser víctimas. Tal reificación torna previsible la felicidad conyugal del narrador.

La regresión final de Anselmo (reducido a la caricatura de niño) muestra una dialéctica entre sistemas (vida matrimonial) y acontecimientos (pérdida $>$ reencuentro del sexo $>$ objeto-fetiche; dominador $>$ dominado; definido $>$ indefinido)

En síntesis: mediante este cuarteto de personajes, que se dicotomizan a través de sus papeles de hombre/mujer, Donoso pretende iluminar la máscara caricatural, ambigua, de las prácticas burguesas en ciertos matrimonios. ¿Hasta qué punto ellos se alienan, al inten- 
tar, simbólicamente, castrarse y dominarse recíprocamente? ¿No es éste un juego de implicación mutua? El resultado es la perplejidad del lector ante lo insólito (fantasmagórico) y la creación de un escenario - texto pleno de fantasmas. Estos se visualizan mediante las transformaciones del sentido.

\section{2. "ATOMO VERDE NUMERO CINCO"}

El nombre de esta "novelita" apunta al objeto - acontecimiento que abrirá factores innovadores en la vida de Roberto y Marta. En efecto, - "ÁTOMO VERDE NUMERO CINCO" — es la denominación del mejor átomo>cuadro, pintado por Roberto. Ilustra la elección, hecha por él y su esposa, del modo de servirse de la estructura social (10)

El cuadro funciona como objeto $>$ evento aleatorio. Enmarca relaciones entre la serialidad de los acontecimientos-catástrofes (robos) y el sistema: perspectiva diacrónica, ambigua, de estados sincrónicos (objetos-fetiches $>$ acontecimientos) Estos últimos, son modificados a través de hurtos imprevisibles, progresivos, de objetos de valor del nuevo "piso" del matrimonio.

Los robos remiten al grado de implicación que instauran las víctimas (la pareja) y los posibles agentes-observadores que podrían efectuarlos. Esto enclava las mutaciones de Marta y Roberto delante de los acontecimientos. La esfera privada de ambos se ve alterada, arbitrariamente, por el embate hostil del universo social (objetos hurtados $>$ eventos-catástrofes)

El nombre del cuadro puede ser asociado, intertextualmente al número atómico de un elemento químico: el boro. El cinco (boro), en la tabla periódica de los elementos, designa formas aleotrópicas (complejas) del estado de la materia. El boro no se encuentra en estado puro ni es soluble en agua; posee una masa atómica, aproximada, de 10,8. Potencialmente, es un material peligroso, capaz de provocar explosiones. Su color es negro o "terroso" Se encuentra en los desiertos. Uniendo las características aludidas a la complejidad de los eventos, advertimos:

A) Que el cuadro, "informalista", abstracto, de Roberto abre la "novelita" Se revela, al inicio, como mini-evento: es el quinto átomo - cuadro pintado por él. Se refiere a uno de los deleites de Roberto: comparar con lupa las líneas de la pintura - recién he-

(10) - Vea el ensayo de Roland Barthes - "Sociología y socio-lógica" In: Barthes, $\mathrm{R}$. et alii - Estructuralismo y sociologia. Trad. esp. de Jorge Giacobbe. Buenos Aires, Nueva Visión, 1973, pp. 9-21. 
cha - con otra, anterior, "químicamente precisa" (p. 108) Esto indiciaría la motivación de la denominación. ÁTOMO VERDE NÚMERO CINCO es el único objeto, al comienzo, "que no estaba totalmente colocado, definido y determinado" (p. 113) Ligando la connotación compleja de esta pintura (11), el título del cuadro funciona en la escritura y en el paradigma químico (el átomo número cinco es el boro) Tal como el boro (materia difícil de individualizar), el cuadro abre un grado de imprevisibilidad para Roberto y Marta: ellos no saben dónde situarlo.

Se torna un micro-evento, pues Roberto lo une a asociaciones rápidas que se borran en la memoria inmediata: discusiones con Marta, originalidad del cuadro, reminiscencia del regalo hecho a su esposa el día del aniversario matrimonial, donación de éste a Marta. Como estos datos se diluyen y el pintor toma la decisión de colgarlo en la puerta de entrada, el cuadro vuelve a ser un mini-evento.

B) Este mini-evento crea implicaciones entre el modo de clasificar la materia y el discurso. El actor-pintor refiere las dimensiones de sua obra $(60 \times 80)$ y su peso: un kilo y ocho gramos $(1,008) \quad$ La factura de la pintura, que él anota en un papelito, establece implicaciones entre la materia química (boro $=$ átomo número cinco $=$ masa atómica $=10,8$ ) y la sensible: el cuadro pesa la décima parte de un átomo número cinco: 1,008. En el sistema cuantitativo, general, de las formas, el cuadro, por su peso, se diferencia del paradigma químico. Se trata de una evocación imprecisa del personaje.

Al final del relato, la anotación hecha sobre el peso de éste, será olvidada por el actor-pintor. Establecerá, por ello, un microevento que le hará buscar una dirección arbitraria: "Peso - la calle -, 108" (p. 171) Es decir. las asociaciones sintagmáticas funcionan en dos sistemas. El olvido del significante químico y su diferencia relativa al nivel del significado: boro $>$ átomo número cinco; masa atómica 10,8 nombre del cuadro: ATOMO VERDE NÚMERO CINCO; peso un kilo y ocho gramos dirección $>$ calle $>$ Peso $>$ número 108 .

Se ven, en síntesis, las diferencias entre el paradigma químico, la escritura y la asociación arbitraria de una dirección.

(11) - Según Barthes, "la sociedad de masas estructura pues lo real de dos maneras concomitantes: produciéndolo o escribiéndo'o". En la "novelita" de Donoso, el átomo, elemento químico - , forma parte de la producción artística de Roberto: es un cuadro. Al mismo tiempo, es un objeto literario. Es necesario, para Barthes, relacionar estas dos estructuras - formas y palabias - para comprender la escritura. Cf. Idem Ibidem, pp. 14-15. 
C) Los colores del cuadro (grupos significantes) establecen ubicaciones en un sistema de diferencias: existe una oposición entre el boro (materia química) >átomo número cinco $<$ colores invariables = negro o "terroso" > opaco >colores neutros y la estructura significante del cuadro. Los colores de éste se implican con el nombre de la pintura, rehecha cinco veces y con el paradigma químico: ÁTOMO VERDE NUMERO CINCO. El verde se intercala, diferenciándose de las asociaciones relativas al boro. El cuadro imprime una marca homóloga entre el paradigma vital del actor-pintor y el espacio de sus objetos-fetiches $>$ muebles. El postula una materia-compuesta, que combine con los "calés" de los muebles y los objetos de su piso. Por ello, el verde se une a los blancos y negros y al ambito café (terroso) de la arpillera.

D) ¿Qué es el arte para Roberto? En la página 109, se refiere que la pintura y la literatura "eran integrantes de la categoría placer" Este odontólogo-artista revela la alienación que le produce la práctica de su profesión (reducida a medio de existencia y obtención de status $>$ fetichismo de la mercadería) y el carácter aleatorio, lúdico, de la pintura: praxis de aficionado. Al no ser asumido en su totalidad, no articula cambios en su estructura vital: lo cosifica aún más. Roberto enclava el arte en el espacio cerrado del departamento, en el cual, dejará un cuarto vacío para instalar, futuramente, su atelier. ¿Hasta qué punto podrá asumir el arte como placer?.

En el relato, la dentística es un micro-evento, que surge y se diluye en la memoria inmediata. En la p. 108, el narrador relaciona ambas actividades:

"La pintura confortaba a Roberto - cosa que no hacía su práctica odontológica, distinguidísima pero quizá demasiado vasta"

Observamos, mediante la ironía, la distinción cualitativa entre odontología ("distinguidísima pero quizá demasiado vasta") y pintura ("confortaba") He aquí la patentización a través del lenguaje de las relaciones alienadas de su trabajo, que lo separan de sí mismo: no le permiten escoger, conscientemente, cómo dirigir su actividad hacia el arte.

Esto se indicia mediante el micro-evento de desear huir del mundo para pintar como Gauguin (pp. 109-112). Esta asociación rápida diferencia su situación de la de Gauguin (paradigma) y la vincula a través del deseo que ambos poseen (sintagma): vivir para solo pintar.

En síntesis: el arte es un objeto reificado más. Funciona en el sistema cerrado, operado por él mismo: el departamento. No consigue 
unir su esfera privada con el universo social: jamás expone sus cuadros fuera de su casa. Por ello, la escritura generará, a partir del robo de su cuadro, acontecimientos, que acentuarán, aún más, el aislamiento de Marta y Roberto en su esfera privada y la incapacidad de ambos para establecer nexos "normales" con el universo social.

La serialidad de los robos y su enumeración pretende marcar la inteligibilidad, cualitativa, que ilustra las diferencias entre las connotaciones que de ellos dimanan. Significan, como fenómeno único, las separaciones entre la esfera privada de la pareja ( $y$, aún, ellos se perciben como diferentes entre sí) y los otros: universo social. Esto pone de manifesto la alienación (12)

Primer robo: el cuadro Impacto sufrido por Roberto, al relacionarse con el agente ("hermano del portero"), que abre la serie de eventos-catástrofes. Se evidencia la interacción entre el cambio externo (la falta del cuadro desarticula el "orden" del piso) y la esfera privada del personaje (sorpresa, indignación). La imprevisibilidad y la sorpresa provienen de la cordialidad desplegada por Roberto en su afán de exhibir el departamento. Se entusiasma porque alguien, que posee "otro estilo de vida", admira su notación social (13) No reacciona por temor a desarticular su universo social delante de sus "nuevos vecinos"

La llegada de Marta realza otro acontecimiento-catástrofe, que se implica con el hurto, al nivel de la representación. Existe un paralelismo entre los robos, que alteran el universo social del matrimonio (agresiones inexplicables, provenientes del exterior) y la esfera privada (al intentar aclarar los eventos-catástrofes, ellos disputarán, progresivamente, para agredirse, al final) Esta constante evidenciará la gradación y la implicación, establecida por los hurtos, en el universo social (se tornarán más desconfiados, aislados y alienados) y en la esfera privada (cada vez, se pelearán más)

Segundo robo: el candelabro. Existe un paralelismo entre este evento-catástrofe y el anterior. En ambos, Roberto exhibe el piso

(12) - Vea, sobre la alienación, la coletánea de E. Fromm, E. Schachtel, Marx et alli - La Soledad del Hombre. Trad. esp. de Santiago González Caracas, Monte Ávila, 1971.

(13) - La actitud de Roberto es propia de entes que pertenecen a "clases superiores". Según Davis y Gardner, éstas ponen el acento en "el nacimiento y en el estilo de vida" El "hermano del portero", en cambio, no puede ser insertado en ninguna clase social, pues no existe la motivación del dinero para el robo, ni se sabe quién es él, lo cual podría situarlo en clases inferiores. Apud. Bourdieu, Pierre - "Condición de clase y posición de clase". In: Bourdieu, P., Barthes, R., et alii - Estructuralismo y Sociología, ed. cit., pp. 98-99. 
cuando Marta no está. El observador pasa a ser, aquí, el posible "implicado" en el hurto. Se advierte una complejidad progresiva. Este evento sucede un día antes de que Marta y, luego, Roberto lo perciban. Por eso, aumenta la sorpresa de Roberto, que "no entiende" lo que su esposa le refiere (p. 135)

Esto crea el setting del acontecimiento y fantasmagoriza lo real, paulatinamente. Los dos cónyugues discuten sobre el sentido de estas peripecias cotidianas y el micro-medio. Especulan sobre los "posibles" sospechosos y el grado inquietante de los eventos.

Tercer robo: la bombilla. La sorpresa disminuye. Antes de salir, Roberto pensó que la ampolleta se había quemado. Se configura una interacción entre los hurtos anteriores (agresiones del universo social) y el retorno precipitado de él (esfera privada alterada por la "sospecha") La remotivación de los robos selecciona "ideas nuevas" sobre el micro-medio. Roberto reconoce una lógica más compleja: imagina una serie de hipótesis fantasmáticas .

Una de ellas es el "miedo" de no encontrar "su piso" (p. 141) El departamento y sus objetos-fetiches se tornan el fantasma de lo real. Roberto organiza, inconscientemente, las transformaciones de su universo social (deja de trabajar, se aísla y se aliena aún más) y de su esfera privada (captación de "otra cosa" detrás de los robos $>$ lo fantasmagórico; peleas más violentas con Marta) La redundancia de los eventos-catástrofes, su no comprensión, desorienta a los personajes, al narrador y a los lectores. Son "gestos de escritura", que marcan lo fantasmagórico: desdoblan la narrativa, mediante la serialidad.

Cuarto robo: los cuatro pisapapeles victorianos. Este eventocatástrofe ocurre ante la vista del matrimonio, que recibe a cuatro predicadores. El narrador los muestra a través de metonimias $>$ "gestos de escritura": "cuatro sonrisas plácidas" $>$ "cuatro voces gentiles"> "registros de las cuatro voces" (pp. 146-147) Estas connotaciones se yuxtaponen "a los ojos despavoridos de Marta y Roberto" (p. 146) El cotejo de ambos tipos de "gestos de escritura" instaura una gradación, que problematiza la ambiguiedad fantasmagórica de la situación. A la "seguridad" de los "cuatro mamarrachos", el narrador nivela el "horror" de Roberto, su desprecio (él los considera "espantapájaros") y la falta de autodominio de la pareja: los dejan entrar y luego los echan.

Roberto, al igual que en el primer evento-catástrofe, no sabe cómo se deja robar $>$ siente estupor $>$ pelea con Marta>le rompe el vestido $>$ lo arroja al fuego. El malestar de la pareja, la progresión de robos inexplicables, le confiere a lo real un sentido y un no sentido 
al mismo tiempo (14) El horror paulatino enclava el ángulo fantasmagórico de lo real.

Quinto robo: el mueble de laca japonesa. Al comprobar que "no eran robos. O eran robos que no eran robos" (p. 156), la pareja sale en busca de ayuda. Perciben que están ante una realidad "inquietante", que no pueden explicar. El acontecimiento de salir se implica con el mini-evento de ver el hurto del mueble, con la reacción de Marta ("impotente", p. 157), que es idéntica a la de su esposo, al atropello que padece y a la pérdida de la última falange del dedo meñique.

Estos mini-eventos traban el "miedo" de la pareja: en el hospital, desean obliterar el retorno al departamento, que se ha tornado el fantasma de los robos (eventos-catástrofes) El escenario>texto departamento) revela las transformaciones de un mundo fantasmático, que crea una relación "inexplicable", fantasmagórica, para los personajes y el lector virtual.

Sexto robo: la linterna. Este mini-evento es retenido, al inicio, en la duración del ver dormir a Marta. Roberto concatena el hurto $>$ universo social y la esfera personal; del no haberle dado hijos, se patentiza la ambivalencia con que el marido piensa en su mujer: "odiosa y cobarde" (p. 163) Este oximoron reitera la memorización de los robos y la hostilidad creciente entre ambos. Al despertar, Marta le confiere a la serialidad de robos un origen centrado en el modo de ser de su marido: "Son culpa tuya porque eres un egoísta como todos los hombres" (p. 164) Del cotejo entre ambas actitudes, captamos los "gestos de escritura" y la gradación de las relaciones ambiguas en la esfera íntima y el universo social. Así se enclava lo fantasmagórico en lo real. Roberto se desorienta $>$ se torna más violento con Marta>desea ignorar los eventos-catástrofes > desea encerrarse en el "cuarto vacío" Lo fantasmagórico se mediatiza en el espacio-escritura, a través de asociaciones aleatorias que las víctimas hacen de un mismo evento.

Séptimo robo: la turmix. La concatenación de los acontecimientos-catástrofes une este hurto al siguiente. Marta asume éste, como micro-evento: descodifica, durante algunos minutos, las reacciones previsibles de su esposo, relativas a la masa de mini-eventos captados en bloque: la agente-observadora (Sra. Presen) y su familia "miserable", con la ayuda del portero, serían los "implicados" por ser "gente pobre" (p. 167)

(14) - Cf. Bellamin-Nöel, J. artL cit., pp. 6-10. 
Octavo y noveno robo: una litografía de Saura (Anselmo) y una crema contra las pecas (Magdalena) Se evidencia, aquí, una dialéctica entre el hurto anterior, hecho por la empleada (figura recurrente en las novelitas >clase baja) y éste, efectuado por sus amigos (también, personajes de las "tres novelitas">clase alta) Esto le confiere a los eventos-catástrofes connotaciones más complejas. Los robos se tornan fantasmas y las situaciones, provocadas por ellos, en la esfera íntima de la pareja, que "no comprende" sus motivaciones, fantasmagoriza lo real, recreando las transformaciones lúdicas del universo social.

Los acontecimientos han operado la dialéctica del sistema, alterando la esfera privada del matrimonio (se aíslan totalmente, alienación progresiva) y su universo social (desconfían hasta de sus amigos, no los llaman) La "peligrosidad" de los otros lleva al evento anhelado, antes, por Roberto: la reclusión en el cuarto vacío, que es el fantasma de su actividad de pintor. Esta fuga es recurrente en Donoso. En Coronación (1958), Andrés Ábalos se aísla y, como su abuela, enloquece, al tener que enfrentar el desamor, el robo y el engaño, coordinados por Estela, la empleada. Lo mismo ocurre en $E l$ Obsceno Pájaro de la Noche (1970) Allí, el Mudito se transforma en una "vieja más", encerrada en un asilo. Su respuesta a la agresión y degradación, a que lo somete la familia de los Azcoitía, es la autoalienación.

Al final del relato, la serialidad se neutraliza. Roberto olvida el origen del papelito que escribió al inicio sobre las dimensiones y el peso del cuadro. Lo singulariza como dirección. Roberto altera su esfera privada y su universo social: le habla a Marta $>$ deciden salir $>$ se tornan aliados. Este mini-evento (la salida) da lugar a otros más complejos: el chofer de taxi es asociado con "el hermano del portero"; hasta el narrador lo denomina así (p. 182) La ayuda de éste será interpretada, arbitrariamente, como "peligrosa" El chofer de observador pasará a ser víctima: será agredido por la pareja.

Esto le da más realce al evento ulterior: los esposos se crearán entre sí un mini-evento-catástrofe: pelearán hasta destruirse la ropa y sangrar. Este mini-evento sintetiza la suma global de las características sociales: las agresiones fantasmáticas (hurtos) del universo social se tornarán aleatorias en la esfera privada del matrimonio.

La respuesta, que ambos encuentran, delante de lo fantasmagórico y lo inexplicable de lo real, será la agresión mutua. Este dato violento surgió en cuentos iniciales de J Donoso ("El Charleston"; 1950); en su novela El Lugar sin Límites (1967), marcando la alienación por la bebida y el machismo. 
Pero, a diferencia de tales relatos, lo fantástico ilumina, aquí, otras pregnancias ideológicas, pues la visión de mundo del autor pretende mostrar el ciclo humano del sistema burgués. El no comprender lleva al aislamiento>agresión >alienación.

\section{3. "Gaspard de la Nuit"}

Una redundancia de las "novelitas" de Donoso, revela que un objeto artístico (canción, cuadro y, aquí música de Ravel) injerta acontecimientos aleatorios. Se unen los lenguajes musicales y plásticos a la referencia de alienaciones y subversiones del mundo. Esta ambivalencia señala la modernidad, según Barthes: el ángulo subversivo señala "el lugar de una pérdida, de una hendidura, el corte, el fading que se apodera del sujeto en la cima de la fruición". En Donoso, esta percepción está dada por la ambigüedad, lo insólito, que los eventos-catástrofes-aleatorios, enmarcan. Barthes afirma, además, que "la cultura retorna como margen: bajo qué forma no importa" (15) Tal vez, así se explica la denominación de "novelitas", conferida a estos relatos breves.

Sobre todo, interesa subrayar que "Gaspard de la Nuit" nos enfrenta con dos niveles de realidad y dos sistemas de vida: el de Mauricio y el de su madre. Visualizamos esto, por la división de la novelita en cinco partes, que se alía a la composición raveleana, creada, casi siempre, con cinco pentagramas ( pautas) y, además, porque Mauricio silba su música. Paolo (intelectual recurrente en las novelitas) descodifica el enigma del silbido de Mauricio, afirmando:

"¿Sabías que Ravel, a veces escribía esas armonías aparentemente tan simples en cinco pentagramas paralelos, y que es dificilísimo interpretarlas"? (pp. 226-227)

Tal "gesto de escritura" articula la deixis de la motivación del relato, dividido en cinco capítulos, así como la estructura musical de Ravel. El nombre de la obra ("Gaspard de la Nuit") adquiere sentido si relacionamos la fusión entre la esfera íntima de Mauricio (que le gusta tal composición) y su universo social (su nombre es idéntico al de Ravel; como el compositor, parece "enigmático" a los otros) La música subraya la complejidad, abstracta y, a veces, simbólica de Mauricio. Ravel, así como los músicos de su período, se basó en poetas simbolistas, para iniciar un estilo sensorial, "decadente"

El otro sistema equivale a Sylvia. Posee una esfera privada organizada (relaciones con Ramón) y un universo social determinado (es modelo) El hiato emerge con la llegada de Mauricio. Este mini-

(15) - Vea el libro ya citado: O Prazer do Texto, pp. 12-13. 
evento le provoca sorpresa a Sylvia, pues amenaza desorganizar-reorganizar, contingentemente, su vida. Ello crea el setting del relato. Organiza implicaciones: una alteración no deseada de su esfera privada por la presencia sorpresiva de un agente-observador: su hijo (esto atenuará sus relaciones con Ramón) Lo mismo ocurre en su universo social: no podrá hacer lo que le resultaba habitual. Ella se siente "víctima" El hijo aporta "novedades"; se torna un emisario de otro medio social. Intenta crear su propio sistema.

El deseo de entenderlo de Sylvia y de su familia es, para él, "una violación" Articula relaciones originales con los otros (miradas, silbidos, pp. 215-219) No permite a nadie adensarse en su esfera íntima; en cambio, desea "rozar los límites de la conciencia de esa persona desconocida", dejar "que su conciencia absorbiera a la otra" (pp. 213-214) Así se revela la metaforización de su esfera íntima. Los "gestos de escritura" subrayan la duplicidad del yo observador víctima: su perplejidad, al vislumbrar el "terror" de los otros, cuando perciben su mirada ( $p$. 213). Esto desorienta a los personajes y al lector virtual, pues lo real se fantasmagoriza.

La creación de un contexto fantástico lo percibimos en la metáfora del "ahorcado" Ella enmarca relaciones ambiguas entre el señor del traje café y el joven (pp. 220-223) Esta imagen se une a la música (silbidos del muchacho $>$ deseo de dominar al otro a través de la música) y a la ambivalencia de su esfera privada, que sólo anhela establecer "semirrelaciones" con personas de la calle (p. 214). Selecciona "ideas", canales originales de comunicación (silbidos, miradas), que lo autoalienan: disocia su esfera privada del universo social de los otros. La escritura recrea, fantasmagóricamente, la realidad/irrealidad de su encuentro enigmático con lo real, mediante imágenes.

Paralelamente, se instaura la organización inconsciente, fantasmática, que pretende organizar el adolescente, poniendo en juego sus deseos. Advierte las transformaciones de un mundo aparentemente lúdico: señora de gafas $>$ huye > siente "terror" (p. 215); hombre del traje marrón $>$ pende de la horca $>$ se independiza del paso del ahorcado>"no alcanzó a colgar" $>$ "es un condenado mudo" $>$ Mauricio huye de la "máscara insinuante"> siente "temor" (pp. 221-222).

Los deseos de Mauricio, observador de sus "víctimas", son inconscientes (dominar $>$ ahorcar a los otros) En el segundo ejemplo, él pasó de observador a víctima, ambivalentemente. El temor de la señora con gafas enclava el paralelismo con la segunda secuencia, en la cual, él acaba sintiendo "temor" de la "mirada procaz" del otro. Se transgrede lo real a través de imágenes que muestran/ ocultan su deseo de "atar el nudo mágico" (p. 222) Surgen los 
fantasmas, que recrean el juego ambivalente de la representación: deviene un fantasma más para Mauricio. Estos datos nivelan lo lúdico de la escritura con las verdades ambivalentes poetizadas en la esfera intima del adolescente. Se estructuran duelos simbólicos, conjunciones semánticas, entre Mauricio, su madre y el muchacho del parque. Se trata de la presencia de lo fantasmático en el espacio íntimo de Mauricio (texto + escenario), transpuesto en el espacio-escritura (16) Ellos son diferenciales, según la instancia discursiva que sea analizada.

$$
\begin{aligned}
\text { Duelo simbólico }_{1},- & \text { Mauricio }>\text { Madre } \\
& \text { aislamiento + deferencia }+ \\
& \text { incomunicación }+ \text { comunicación }+ \\
& \text { invulnerabilidad }+ \text { vulnerabilidad }+ \\
& \text { desagrado }+ \text { terror. }
\end{aligned}
$$

El narrador advierte, reiterativamente, que Mauricio se sentía "agredido por el beso de su madre" (p. 223), "violado" (p. 224); excluido "de las máscaras y disfraces de su madre" (p. 226). En el cuarto capítulo = pentagrama, el hiato entre estos dos sistemas se hará máximo. Se concatena el mini-evento-catástrofe - "ser violado" con el papel de observadora, asumido por Sylvia: lo critica, desea "perfeccionarlo", insertarlo en su universo social. Esto provoca las precisiones que le hace Mauricio: la música de Ravel "no es su esencia", sino "un camino" (pp. 257-260) De allí, surge el reconocimiento del adolescente: jamás podrá conciliar su esfera privada con el universo social de Sylvia y la familia. Tal conjunción semántica puede ser esquematizada, así:

$$
\begin{aligned}
& \text { Duelo simbólico }_{1 \text {, }} \text { - Madre > Mauricio } \\
& \text { incomprensión + comprensión + } \\
& \text { interés }+ \text { rechazo }+ \\
& \text { deferencia }+ \text { indiferencia }+ \\
& \text { castradora + castrado. }
\end{aligned}
$$

Deviene de esto, su transformación externa>universo social (muchacho de clase alta $>$ clase baja e íntima $>$ esfera privada evocación del vagabundo $>$ intercambio de miradas y silbidos $>$ intercambio de ropas y personalidades, pp. 260-266)

Este cruce del bagaje humano evidencia la autoalienación de Mauricio, su deseo de evasión para evitar conflictos interpersonales (17).

(16) - Cf. Bellamin-Nöel, J., art. cit., pp. 7-12.

(17) - Vea el ensayo de Frederick A. Weiss - "Dinámica y Terapia de la Autoalienación" en el libro ya citado: La Soledad del Hombre, pp. 243-265. 
Su autoeliminación del universo social, familiar, patentiza el deseo de articular un yo ideal: desea ser otro para ser él mismo. Esto puede ser analizado a través del duelo simbólico entre él y el muchacho del parque, que en virtud de la semejanza, adquirirá el yo repudiado por Mauricio.

$$
\begin{aligned}
& \text { Duelo simbólico } 2 \text { - Mauricio } \cong \text { vagabundo } \\
& \text { enseñar }+ \text { aprender }+ \\
& \text { corregir }+ \text { ser corregido }+ \\
& \text { evocar }+ \text { esperar }+ \\
& \text { observar + dormir + } \\
& \text { dormir }+ \text { observar }+ \\
& \text { autoeliminarse }+ \text { autoalienarse }+ \\
& \text { huir }+ \text { regresar. }
\end{aligned}
$$

El retorno del "otro Mauricio" reorganiza el sistema. Sylvia (personaje de la primera novelita), podrá, ahora, implicar su universo social y su esfera íntima con el "nuevo Mauricio" La mutación se articula en la esfera íntima: el vagabundo no asumirá el papel de observador = víctima del Mauricio verdadero. Aceptará, pasivamente, las novedades que el micro-medio burgués le ofrece: una moto, camisas llamativas, seguridad. Mauricio provoca respuestas al topos social, mediante el accidente - acontecimiento del cambio de personalidades Proporciona la dialéctica del desear ser dirigido, determinado y protegido por el universo social burgués (vagabundo) y el desear autoeliminarse de él, ser indeterminado, otro; seguir el camino elegido, aleatorio, de la huida (Mauricio) Ocurre un intercambio entre sistemas de vida (burguesía $>$ clase baja; Mauricio <clase alta $>$ clase baja) Mauricio rechaza el sistema burgués, pero su fuga es una forma de autoalienación. El fantasma de las identidades y lo insólito del final revelan la no adecuación entre designación y significación. Esto es proprio de lo fantasmagórico.

\section{Conclusiones. Las "Tres Novelitas" y la narrativa de Donoso.}

En Tres Novelitas Burguesas, Donoso redistribuye algunos eventos de su narrativa anterior. Diseña otro margen significante para sus relatos. Su modernidad proviene de esta ambivalencia: instaurar destrucciones indirectas, dinámicas, para crear una nueva mímesis (18) Podemos identificar, por ejemplo, el deseo de huir del mundo (como Gauguin) de Roberto ("ÁTOMO VERDE NUMERO CINCO") con el desfile de lugares imaginarios: "China", relato aparecido en Anto-

(18) - Cf. Barthes, Roland - O Prazer do Texto, ed. cit., pp. 11-15. 
logía del Nuevo Cuento Chileno, 1954 (19); espacio inventado por un niño (fascinante, distinto, libertad, aventura) y, luego, olvidado por el adulto, que se aliena. En Coronación (1958), Andrés crea "Omsk" (clase alta) y Mario, "Oslo" (clase baja). Los olvidan. Se refiere, así, la zona de la alienación en la esfera íntima. En este libro de 1958, se había historicizado el afán coleccionador de Andrés Ábalos (bastones) En las novelitas, Marta y Ramón articulan el "fetichismo de la mercadería" La quiebra, en relación a Coronación, proviene de la serialidad fantástica de hurtos.

"Chatanooga Choochoo" tiene su antecedente en el cuento "El Charleston" (1960), en el cual encontramos la caricatura de un gordo que baila, el machismo y la muerte de la víctima. La transgresión, en las novelitas, resalta la simbiosis, original, de la alienación, lo fantástico y la explotación de relaciones matrimoniales, ausentes en el relato de 1960. "Gaspard de la Nuit" puede vincularse a "La Puerta Cerrada", uno de los cuentos del volumen El Charleston (1960), pero publicado un año antes, en otra antología del grupo del 50. Ambos personajes son considerados "locos" por sus madres y malogran sus relaciones con el universo social (autoalienación) La novedad de la "novelita" es la ambigüedad fantástica que ilumina máscaras alienadas y acentúa el sistema burgués. Lo fantástico surge, unido a la alienación, en El Obsceno Pájaro de la Noche (1970), en la obra de José Donoso. Allí encontramos la regresión del Mudito (nene, pp. 122126), su castración, su mutación, su autoalienación y muerte ulterior. Estos factores son reorganizados en el libro analizado.

En las "novelitas", hay personajes recurrentes: la Sra. Presen (empleada), Paolo Rojo (intelectual snob y homosexual, que consuela a las mujeres cuando tienen problemas) Marta y Roberto aparecen en la novela inicial y final, como amigos de Ramón y Sylvia, protagonistas de ambas y, en la central, ocupan el primer plano, llamando a Anselmo (médico), personaje de la primeira. Donoso crea nexos entre los personajes. Traba, así, el carácter aleatorio de los eventos. Estos connotan el mundo burgués, su complejidad fantástica ambigua y alienada.

(19) - Esta antología reunía a los escritores de la "generación del 50", que pretendían acabar con el regionalismo. Donoso continuó solo. Vea la primera edición, organizada por Lafourcade, Santiago de Chile, Zig-zag, 1954 pp. 75-82. 